\title{
Primary mediastinal large B-cell lymphoma in HIV: report of two cases
}

\author{
Katalin Kelemen • Wendy Cao • LoAnn C. Peterson • \\ Andrew M. Evens $\cdot$ Daina Variakojis
}

Received: 3 October 2008 / Accepted: 28 December 2008 / Published online: 28 February 2009

(C) Springer-Verlag 2009

\begin{abstract}
Primary mediastinal large B cell lymphoma (PMLBCL) is a subtype of diffuse large B cell lymphoma arising in the mediastinum with distinctive clinical and morphological features. Though diffuse large B cell lymphoma is one of the most common non-Hodgkin lymphoma associated with AIDS, there are no data available regarding the association of HIV and PMLBCL. We report here two cases of PMLBCL arising in AIDS patients. In both cases, PMLBCL presented in a setting of low CD4 T-cell count as rapidly enlarging mediastinal mass. The morphologic and immunophenotypic findings are characteristic of PMLBCL. One of the two patients, a 25-year-old woman who had localized disease and evidence of Epstein-Barr virus in lymphoma cells, did not respond to chemotherapy and died of disease progression 5 months after diagnosis. The second patient, a 38-year-old male with disseminated disease, responded to therapy and is diseasefree after 9 months of follow-up.
\end{abstract}

Keywords Primary Mediastinal Large B Cell Lymphoma . HIV. EBV

K. Kelemen $(\triangle) \cdot$ W. Cao $\cdot$ L. C. Peterson $\cdot$ D. Variakojis

Department of Pathology, Northwestern Memorial Hospital, Northwestern University Feinberg School of Medicine,

251 E. Huron Street, Feinberg-7-302,

Chicago, IL 60611, USA

e-mail: katikelemen99@yahoo.com

\section{A. M. Evens}

Division of Hematology-Oncology, Northwestern Memorial Hospital, Northwestern University Feinberg School of Medicine, 251 E. Huron Street, Feinberg-7-302,

Chicago, IL 60611, USA

\section{Introduction}

The incidence of non-Hodgkin lymphoma (NHL) is 100 200-fold higher in HIV-infected individuals than in the general population. NHL is an AIDS-defining illness and in $3-5 \%$ of cases, the lymphoma is the initial manifestation of AIDS [1]. The most common HIV-associated lymphomas are diffuse large B cell lymphoma (DLBCL; often primary in the central nervous system), Burkitt lymphoma, primary effusion lymphoma, and plasmablastic lymphoma of the oral cavity [2]. Primary mediastinal large B cell lymphoma is a subtype of diffuse large B cell lymphoma arising in the mediastinum with distinctive clinical, morphologic, and genotypic features [3]. Most patients are young adult females presenting with localized mediastinal mass and symptoms often related to local effects of the large mediastinal tumor such as superior vena cava syndrome. DLBCL is one of the most common lymphomas in the setting of HIV, but the incidence of PMLBCL in HIV is not well established. Only one reported case of HIV-associated PMLBCL has been found in the English literature [4]. We report here two additional cases of PMLBCL arising in AIDS patients.

\section{Case reports}

Case 1

A 25-year-old female presented to her physician with 1 week of worsening shortness of breath, cough, and chest pain. She gave birth to her fourth child 5 weeks ago, and her cough and shortness of birth was developed a few days prior to delivery. She was diagnosed with HIV 1 year before; however, she had no previous manifestation of 
AIDS. She was on azathyoprine while pregnant. Her last CD4 count was $152 / \mu \mathrm{L}$ and her LDH was 379 . Chest computed tomography (CT) revealed a $13.7 \times 9.2-\mathrm{cm}$ superior mediastinal mass, multiple left pleural masses ranging from $2.4-2.7 \mathrm{~cm}$, a $1.6-\mathrm{cm}$ left upper lobe lung nodule, and bilateral pleural effusions (Fig. 1). She underwent mediastinoscopic biopsy of the mass. Pathologic examination showed varying degrees of fibrosis associated with lymphoid infiltrate. The infiltrating cells were mostly large with irregular and convoluted vesicular nuclei, 1-3 visible nucleoli, and moderately abundant cytoplasm. Many cells showed prominent pink nucleoli. Small areas of necrosis were present, and scattered mitotic activity was seen. The tumor cells were $\mathrm{CD} 45+, \mathrm{CD} 20+, \mathrm{CD} 23+$, partially $\mathrm{CD} 30+$, weak partial positive for $\mathrm{Bcl}-2$ and $\mathrm{Bcl}-$ 6, and negative for $\mathrm{CD} 3, \mathrm{CD} 5, \mathrm{CD} 10, \mathrm{CD} 15, \mathrm{CD} 21$, and ALK-1. EBER in situ hybridization was positive in approximately $30 \%$ of the tumor cells (Fig. 2). Flow cytomeric immunophenotyping showed a decreased CD4/ CD8 ratio of 0.3 and evidence of an abnormal B cell population with expression of CD19 and CD20 but lack of surface immunoglobulin light chain expression. A diagnosis of primary mediastinal diffuse large B-cell lymphoma was rendered. Subsequent staging bone marrow biopsy did not show involvement by lymphoma. Lumbar puncture and a magnetic resonance imaging of the brain showed no evidence of central nervous system involvement of lymphoma. The patient was treated with 3 cycles EPOCH chemotherapy. Her symptoms initially improved; however, after the third cycle, her disease progressed and the treatment was changed to VP-16, Ifosfamide, and Ara-C with concurrent mesna. Her symptoms continued worsening and she died of respiratory failure 5 months after the diagnosis of the lymphoma.

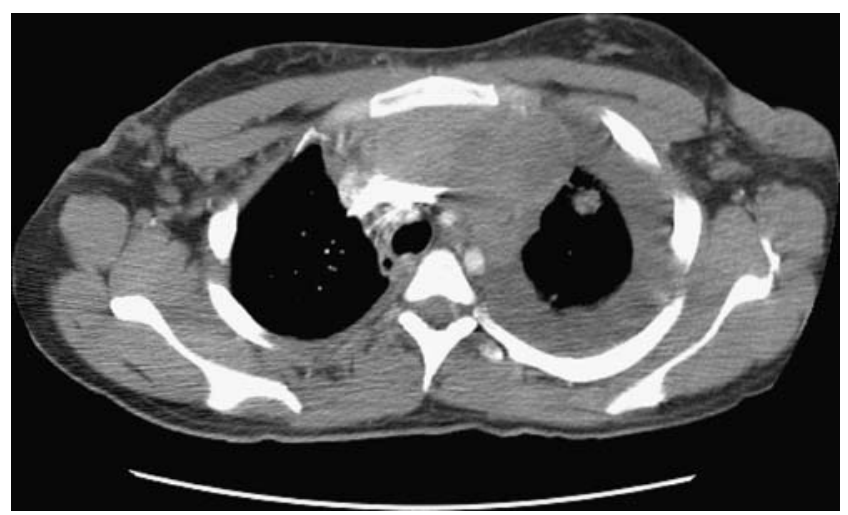

Fig. 1 Chest CT of Case 1 reveals a $13.7 \times 9.2-\mathrm{cm}$ superior mediastinal mass, multiple left pleural masses ranging from 2.4$2.7 \mathrm{~cm}$, a $1.6-\mathrm{cm}$ left upper lobe lung nodule, and bilateral pleural effusions
Case 2

A 38-year-old male with history of HIV for 7 years and no prior AIDS-defining illness presented with complaints of progressive shortness of breath for 10 days and one episode of fever 2 weeks prior to the onset of his symptoms. He had night sweats for about 3 years, but he denied weight loss, cough, or hemoptysis. On admission, his laboratory values showed a CD4 count of $140 / \mu \mathrm{L}$ and a markedly elevated LDH value of 886. Imaging studies of the chest revealed an abnormal cardiomediastinal silhouette caused by a large left-sided mediastinal mass extending within the superior hemithorax medially. In addition, large left-sided pleural effusion was present, and several nodular opacities were noted in the left lung (Fig. 3). The patient was admitted, and highly active antiretroviral therapy (HAART) was started. Subsequently, direct biopsy of the mass was performed by mediastinoscopy. The biopsy showed a variably dense lymphoid infiltrate composed of large lymphoid cells with abundant pale cytoplasm, pleomorphic nuclei which focal clusters, and rounded nests surrounded by delicate fibrous bands. Frequent mitoses, including atypical mitotic forms, were present. Immunohistochemistry showed that the tumor cells were positive for CD45, CD20, CD30, Bcl-2, and Bcl-6, were focally positive for $\mathrm{CD} 23$, and were negative for cytokeratin, CD3, CD10, CD15, and ALK-1. EBER in situ hybridization was mostly negative, with only very rare scattered positively staining cells (Fig. 4). Flow cytometric analysis showed a population of $\mathrm{T}$ lymphocytes with a CD4/CD8 ratio of 1.4 , but no discrete $\mathrm{CD} 19+$ or $\mathrm{CD} 20+\mathrm{B}$ cell cluster was identified. The overall findings were diagnostic of a primary mediastinal large B cell lymphoma. A bone marrow biopsy showed hypercellular bone marrow with no evidence of lymphoma. A positron emission tomography scan, however, revealed multifocal extranodal thoracic, both nodal and extranodal abdominal, and possible acetabular involvement by the lymphoma. The patient was treated with steroids followed by combination chemotherapy with Rituxan-hyperCVAD/ intrathecal metothrexate in addition to HAART and antimicrobial medication including bactrim, acyclovir, and diflucan. After 2 cycles of therapy, the mediastinal mass decreased in size, and the LDH level dropped to 168 . The patient responded well to the therapy and after 9 months of follow-up, he is without detectable disease.

\section{Discussion}

The World Health Organization classification of hematopoietic malignancies recognizes AIDS-associated lymphomas as a specific category to acknowledge the significant impact of HIV on the pathophysiology and prognosis of 
Fig. 2 Pathologic examination of Case 1 shows varying degrees of compartmentalizing fibrosis associated with lymphocytic infiltrate. The infiltrating cells are mostly large with irregular and convoluted vesicular nuclei, 1-3 visible nucleoli, and moderate cytoplasm. The tumor cells are strongly positive for CD20. EBER in situ hybridization is positive in approximately $30 \%$ of the tumor cells

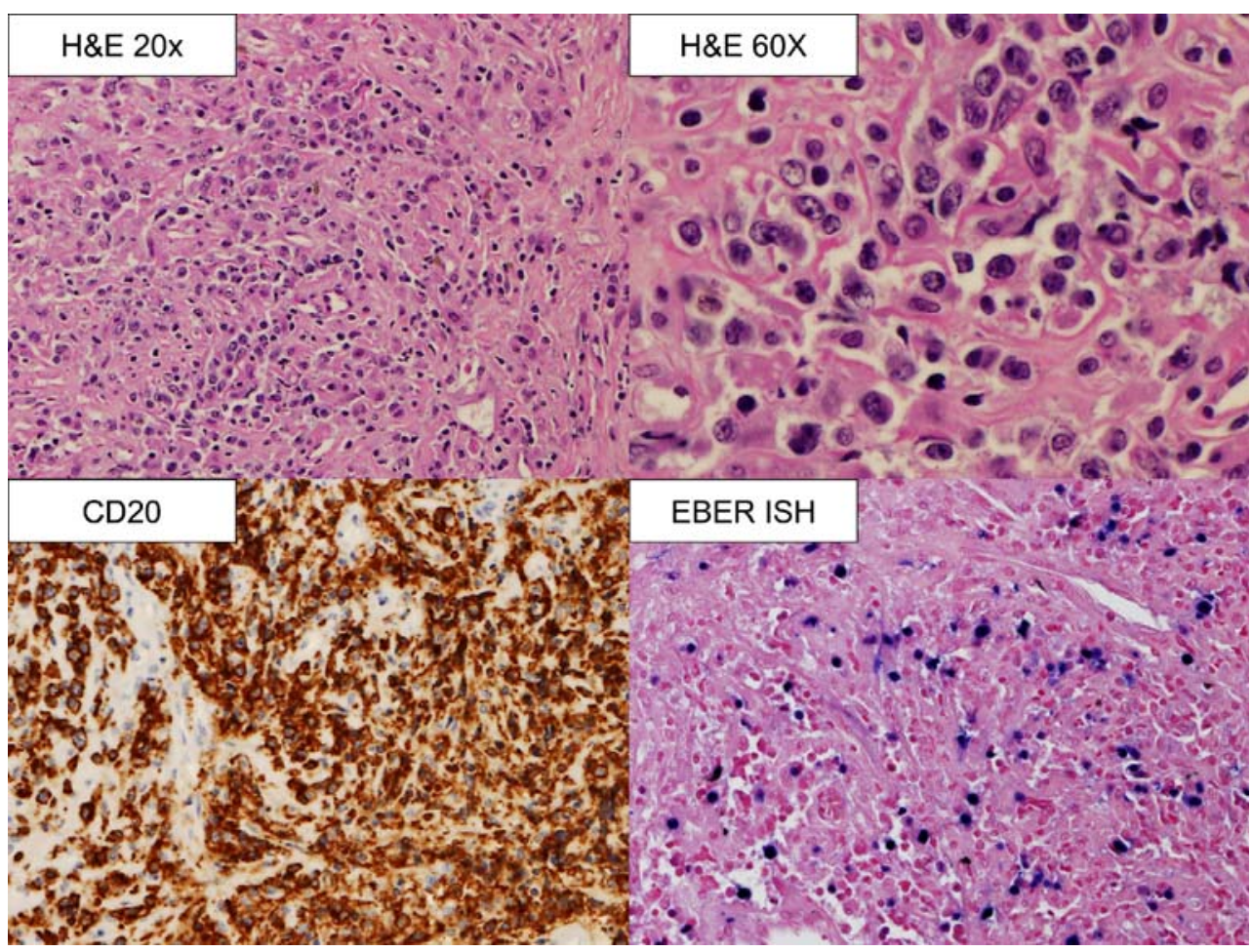

lymphomas [2]. The pathogenetic mechanisms contributing to lymphoma genesis are complex and include chronic antigen stimulation, genetic abnormalities, cytokine dysregulation, and the role of herpes viruses: Epstein-Barr virus (EBV) and Kaposi Sarcoma Human Virus (KSHV, HHV8) [5]. The overall survival of patients with HIV-related NHLs is inferior compared to HIV-negative patients, and in HIV, the majority of patients present with widespread disease and with higher risk for central nervous system involve-

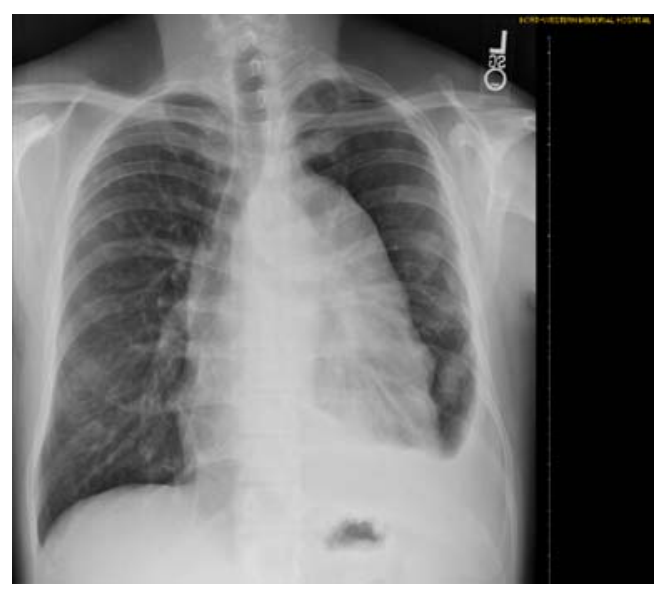

Fig. 3 Chest X-ray of Case 2 shows an abnormal cardiomediastinal silhouette caused by a large left-sided mediastinal mass extending within the superior hemithorax medially. In addition, large left-sided pleural effusion is present, and several nodular opacities are noted in the left lung ment. The introduction of HAART extended the lifespan of AIDS patients and some studies indicated a decrease of the incidence of lymphomas in AIDS since widespread availability of HAART [6]. The combination of HAART with aggressive chemotherapy, such as CHOP, not only is tolerable and effective treatment in patients with HIV and NHL but the initial good response to HAART is also associated with higher complete response rates to the chemotherapy ( $77 \%$ response to $\mathrm{CHOP}$ versus $50 \%$ in nonresponders) [7]. The association between HIV and classical Hodgkin lymphoma is less clear, and, unexpectedly, the incidence of Hodgkin lymphoma in AIDS has increased since HAART was introduced [8]. Of note, HIVrelated Hodgkin lymphoma is associated with EBV in nearly all cases [9], and it has been postulated that the EBVencoded latent membrane protein (LMP1; which is functionally homologous to activated CD40), is essential to the antiapoptotic phenotype of the Reed-Sternberg cells, replacing the $\mathrm{CD} 40 / \mathrm{CD} 40$ ligand interaction by $\mathrm{CD} 4+\mathrm{T}$ cells, which are decreased in AIDS [10].

Though diffuse large B cell lymphoma is one of the most common NHL associated with AIDS, there are virtually no data available about the association of HIV and PMLBCL. So far, only one case of PMLBCL has been described in the literature in the setting of AIDS [4]. This patient, a 29-yearold woman with 12 years of history of HIV infection without prior AIDS-defining illness, presented with fever, night sweats, cough, and a CD4 count of $316 / \mu \mathrm{L}$. HAART therapy was initiated but had to be discontinued within a 
Fig. 4 Microscopic sections of Case 2 show dense lymphoid infiltrate composed of large lymphoid cells with abundant pale cytoplasm, pleomorphic nuclei which form clusters and rounded nests surrounded by delicate fibrous bands. Frequent mitoses, including atypical mitotic forms are present. By immunohistochemistry, the tumor cells are positive for CD20, CD30, and Bcl-6. EBER in situ hybridization was negative

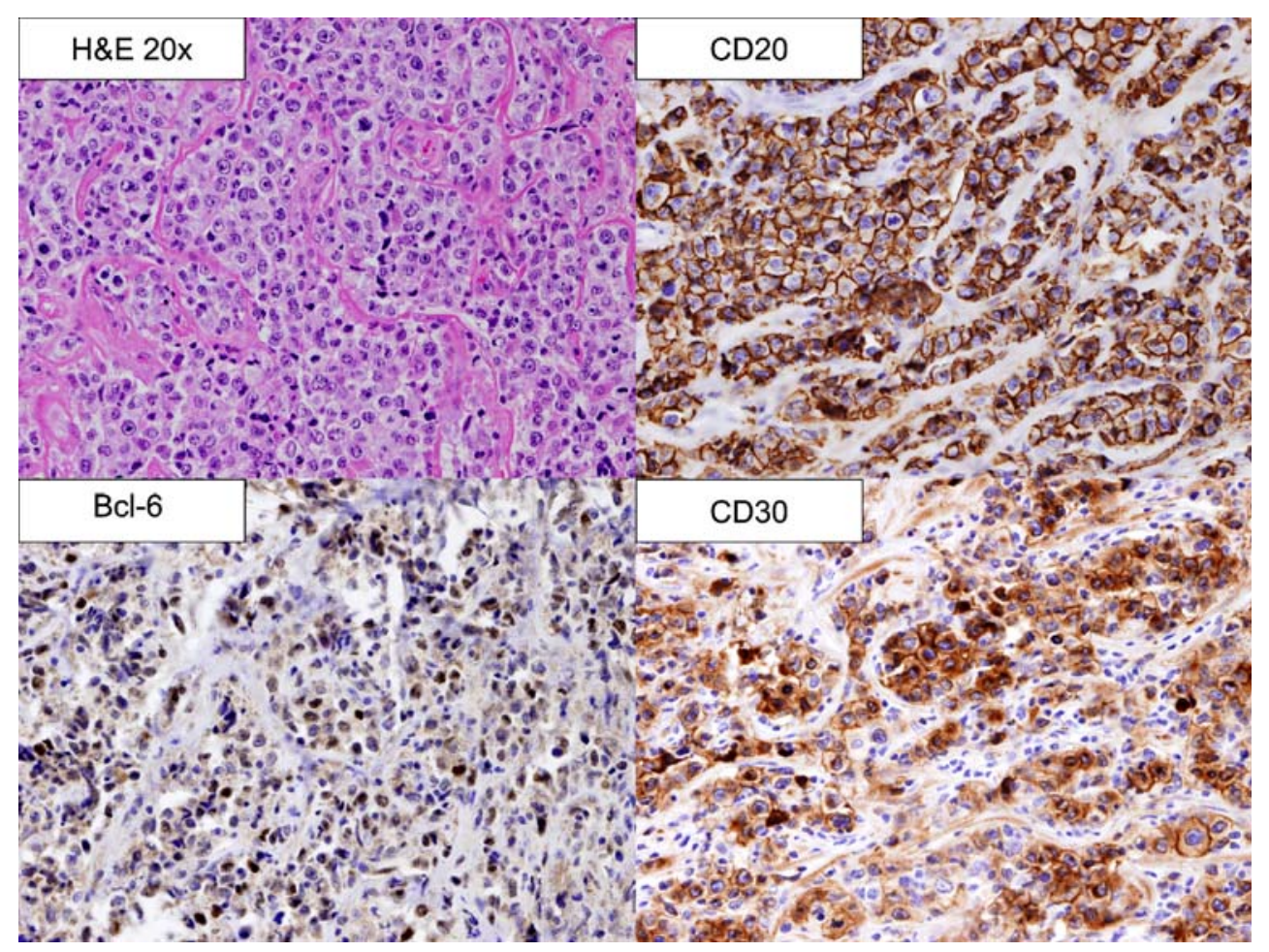

few days due to development of Stevens-Johnson syndrome. Biopsies via mediastinotomy established the diagnosis of PMLBCL, with no evidence of extrathoracic disease upon staging. Chemotherapy with CHOP and granulocyte colony-stimulating factor was started; however, 6 days after the first cycle of treatment, the patient died from neutropenic sepsis.

In our current report, the clinical presentation in Case 1 is classical in terms that the patient is a young woman who presents with a mediastinal mass and her disease is localized to the mediastinum (Table 1 summarizes the clinical findings of Cases 1 and 2 in comparison to the case reported by Milling et al.). This patient was known to have HIV but because she was pregnant, she only received AZT monotherapy and had very low CD4 T-cell count $(152 / \mu \mathrm{L})$ at diagnosis. In contrast, the clinical presentation of Case 2 is unusual in several aspects. The patient is a male and in addition to a large mediastinal mass, he has widespread

Table 1 Comparison of the clinical features of Case 1, Case 2, and the case reported by Milling et al. 2004

\begin{tabular}{|c|c|c|c|}
\hline & Case \#1 & Case \#2 & $\begin{array}{l}\text { Case reported by } \\
\text { Millings et al. } 2004\end{array}$ \\
\hline Age/sex & 25/Female & 38/Male & 29/Female \\
\hline Presentation & $\begin{array}{l}\text { Shortness of breath, } \\
\text { cough, chest pain }\end{array}$ & $\begin{array}{l}\text { Shortness of breath, fever, } \\
\text { night sweats }\end{array}$ & $\begin{array}{l}\text { Fever, night } \\
\text { sweats and cough }\end{array}$ \\
\hline Duration of HIV + status & 1 year & 7 years & 12 years \\
\hline Prior therapy for HIV & Azathyoprine & None & None \\
\hline CD4 count at presentation & $152 / \mu \mathrm{L}$ & $140 / \mu \mathrm{L}$ & $316 / \mu \mathrm{L}$ \\
\hline $\mathrm{LDH}$ at presentation & 379 IU/L (high) & 886 IU/L (high) & 542 IU/L (high) \\
\hline Stage of disease & Stage IV & Stage IV & Not stated \\
\hline Bone marrow involvement & Negative & Negative & Negative \\
\hline Extramediastinal involvement & $\begin{array}{l}\text { Pleural masses, pleural } \\
\text { effusions, left lung nodule }\end{array}$ & $\begin{array}{l}\text { Pleural effusion, left lung nodules, } \\
\text { multifocal abdominal and } \\
\text { acetabular masses }\end{array}$ & None \\
\hline Therapy received & $\begin{array}{l}\text { HAART, } 3 \text { cycles of EPOCH then } \\
\text { VP-16, ifosfamide, ARA-C, mesna }\end{array}$ & $\begin{array}{l}\text { HAART, } 6 \text { cycles of } \\
\text { Rituxan-Hyper CVAD }\end{array}$ & $\begin{array}{l}1 \text { cycle of } \mathrm{CHOP} \\
\text { and } \mathrm{G}-\mathrm{CSF}\end{array}$ \\
\hline Outcome & Death 5 months after diagnosis & $\begin{array}{l}\text { No detectable disease after } \\
9 \text { months follow-up }\end{array}$ & $\begin{array}{l}\text { Death } 6 \text { days after } \\
\text { chemotherapy }\end{array}$ \\
\hline
\end{tabular}


disease at presentation. Similarly to Case 1, he did not receive HAART therapy prior to his presentation and his CD4 T-cell count was low $(140 / \mu L)$. Neither of the two patients had evidence of bone marrow or central nervous system involvement. The immunophenotype of the lymphoma cells of both cases is consistent with previously described phenotype of PMLBCL: CD45+, CD20+, $\mathrm{CD} 23+$, and partially CD30+. In Case 2, but not in Case 1 , the lymphoma cells also express Bcl-6, a finding unusual but not excluding the diagnosis of PMLBCL. An important finding in Case 1 is the EBV positivity in approximately $30 \%$ of the lymphoma cells by EBER in situ hybridization. The role of EBV in the pathogenesis of PMLBCL in the immunocompetent host was previously dismissed. In one study, only two cases were positive for EBV of 41 PMLBCL cases [11]; others reported complete absence of EBV [12]. The previously reported case of PMLBCL in $\mathrm{HIV}$-infected patient also was negative for EBV with EBER in situ hybridization [4]. In our case, it is not clear as to what extent the EBV positivity contributes to lymphoma pathogenesis or represents EBV infection acquired during the course of disease. Yet, the finding of $30 \%$ EBERpositive lymphoma cells is likely to be clinically significant, since Park et al. recently reported that EBER positivity of $20 \%$ or more in lymphoma cells in DLBCL is associated with significantly poorer overall survival and progression-free survival compared to EBV-negative DLBCLs [13]. In the immunocompromised, such as AIDS or post-transplant state, EBV infection even in a minority of lymphoma cells might have significant impact on disease pathogenesis and outcome. Since the molecular signature of PMLBCL resembles that of classical Hodgkin lymphoma [14], EBV infection might contribute to an anti-apoptotic phenotype of the lymphoma cells with a similar mechanism as observed in HIV-associated Hodgkin lymphoma. In our patient with EBV-associated PMLBCL, despite the localized nature of the lymphoma, the tumor continued to progress during chemotherapy resulting in death of the patient after 5 months of diagnosis. Unlike Case 1, Case 2 responded well to a combination of HAART and chemotherapy and improved rapidly, despite widespread disease at diagnosis.

In summary, though increased incidence of PMLBCL has not been established in AIDS due to the rarity of these cases, PMLBCL occurs in HIV and appears to present in the setting of low CD4 T-cell count as a rapidly growing mediastinal mass. A good response to a combination of HAART and chemotherapy can be obtained even in cases with widespread disease. More cases are necessary to characterize the relationship between PMLBCL and HIV and to determine the impact of EBV infection on disease pathogenesis and prognosis in the immunocompromised.

Conflict of interest The authors have no conflict of interest.

\section{References}

1. Levine AM (1993) AIDS-related malignancies: the emerging epidemic. J Natl Cancer Inst 85(17):1382-1397. Sep 1

2. Swerdlow SH, Campo E, Harris NL, Jaffe ES, Pileri, SA, Stein H, Thiele J, Vardiman JW (2008) Lymphomas associated with HIV infection. In: Bosman FT JES, Lakhani SR, Ohgaki H (eds) WHO classification of tumours. WHO classification of tumours of haematopoietic and lymphoid tissues, 4th edn. International Agency for Research on Cancer, Lyon, pp 340-342

3. Swerdlow SH, Campo E, Harris NL, Jaffe ES, Pileri SA, Stein H, Thiele J, Vardiman JW (2008) Primary mediastinal (thymic) large B-cell lymphoma. In: Bosman FT, Jaffe ES, Lakhani SR, Ohgaki $\mathrm{H}$ (eds) WHO classification of tumours. Tumours of haematopoietic and lymphoid tissues, 4th edn. International Agency for Research on Cancer (IARC), Lyon, pp 250-251

4. Milling DL, Lazarchick J, Chaudhary UB (2005) Primary mediastinal large B-cell lymphoma in an HIV-infected patient. Am J Med Sci 329(3):136-138. Mar

5. Gaidano G, Carbone A (1995) AIDS-related lymphomas: from pathogenesis to pathology. Br J Haematol 90(2):235-243. Jun

6. Matthews GV, Bower M, Mandalia S, Powles T, Nelson MR, Gazzard BG (2000) Changes in acquired immunodeficiency syndrome-related lymphoma since the introduction of highly active antiretroviral therapy. Blood 96(8):2730-2734. Oct 15

7. Ratner L, Lee J, Tang S et al (2001) Chemotherapy for human immunodeficiency virus-associated non-Hodgkin's lymphoma in combination with highly active antiretroviral therapy. J Clin Oncol 19(8):2171-2178. Apr 15

8. Biggar RJ, Jaffe ES, Goedert JJ, Chaturvedi A, Pfeiffer R, Engels EA (2006) Hodgkin's lymphoma and immunodeficiency in persons with HIV/AIDS. Blood 108(12):3786-3791. Dec 1

9. Audouin J, Diebold J, Pallesen G (1992) Frequent expression of Epstein-Barr virus latent membrane protein-1 in tumour cells of Hodgkin's disease in HIV-positive patients. J Pathol 167(4):381384. Aug

10. Levine AM (1996) HIV-associated Hodgkin's disease. Biologic and clinical aspects. Hematol Oncol Clin North Am 10(5):11351148. Oct

11. Nakagawa A, Nakamura S, Koshikawa T et al (1993) Clinicopathologic study of primary mediastinal non-lymphoblastic nonHodgkin's lymphomas among the Japanese. Acta Pathol Jpn 43 $(1,2): 44-54$. Jan-Feb

12. Scarpa A, Borgato L, Chilosi M et al (1991) Evidence of c-myc gene abnormalities in mediastinal large B-cell lymphoma of young adult age. Blood 78(3):780-788. Aug 1

13. Park S, Lee J, Ko YH et al (2007) The impact of Epstein-Barr virus status on clinical outcome in diffuse large B-cell lymphoma. Blood 110(3):972-978. Aug 1

14. Savage KJ, Monti S, Kutok JL et al (2003) The molecular signature of mediastinal large B-cell lymphoma differs from that of other diffuse large B-cell lymphomas and shares features with classical Hodgkin's lymphoma. Blood 102(12):3871-3879. Dec 1 